\title{
Особенности интегрированного проектирования гражданских легких самолетов с турбовинтовыми двигателями на этапе предварительного проектирования
}

\author{
Национальный аэрокосмический университет им. Н. Е. Жуковского \\ «Харьковский авиационный институт»
}

\begin{abstract}
Проведен анализ изменений параметров и характеристик гражданских легких самолетов. Предложены новые пути повышения их качества, улучшения тактико-технических и летных характеристик для удовлетворения широкого спектра сфер их применения. Установлены пределы изменения и уточнены статистические диапазоны параметров и характеристик гражданских легких самолетов. Приведены рекомендации по методу определения взлетной массы гражданского легкого самолета с турбовинтовыми двигателями на этапе предварительного проектирования в соответствии с критерием оптимальности минимальной взлетной массой. Описаны особенности программного комплекса и его апробация при разработке аванпроекта гражданского легкого самолета ХАИ-90.

Ключевые слова: гражданский легкий самолет, взлетная масса, этап предварительного проектирования, критерий минимума массы, мастер-геометрия, модель распределения пространства, аналитический эталон, статистическое исследование.
\end{abstract}

Анализ параметров и характеристик гражданских легких самолетов проведен в связи со стремительным развитием науки и техники, которое все чаще диктует современные требования к промышленности; влияет на развитие малой авиации на международном рынке и, в особенности, в Украине. Легкие самолеты применяют для перевозки пассажиров и грузов, почты, патрулирования местности и коммуникаций, медицинского обслуживания населения; первоначального обучения пилота, выполнения тренировочных полетов, а также для воздушной акробатики, организации различных видов досуга и т.д. Характерной особенностью применения таких самолетов является их взлет и посадка как с подготовленных, так и с неподготовленных площадок, особенно в небольших и отдаленных населенных пунктах, в которых нет аэропортов и оборудованных взлетно-посадочных полос.

Специализация предприятий Украины, таких, как Лилиенталь, ООО «Аэропракт», ТММ-Авиа, ХГАПП, ООО «Софтекс-Инвест», ANG Patriot UA, ГП «Одесский авиационный завод», компания «Flight Design» (Херсон) и др., основывается на производстве сверхлегких и легких самолетов с массой коммерческой нагрузки до 500 кг. Кроме того, функционирует ряд предприятий, которые являются дилерами и импортерами легких самолетов в Украину. Удовлетворение широкого спектра сфер деятельности населения приводит к поиску новых путей повышения эффективности авиационной техники (АТ), улучшения ее тактико-технических и летных характеристик.

При этом ведется постоянная модернизация АТ на базе накопленного опыта, инженерных и конструкторских исследований, современных наукоемких компьютерных интегрированных технологий, позволяющих обеспечивать высокое качество проектирования, подготовки производства, инженерного анализа, испытаний, сертификации, информационной поддержки жизненного цикла авиационных комплексов. Степень их внедрения в процесс проектирования, разработки новых методов и совершенствования существующих приводит к 
интеграции технических, гуманитарных, естественных наук и современной техники, теории и практики, что является определяющим фрактором безопасности, эргономики и экономичности при эксплуатации гражданского легкого самолета.

Целью данной работы является определение особенностей интегрированного проектирования гражданских легких самолетов с турбовинтовыми двигателями на этапе предварительного проектирования.

Эволюция развития основных параметров и характеристик самолетов сопровождалась постоянным усложнением и детализацией проработки не только их конструкции, аэродинамической, объемно-массовой и конструктивно-силовой компоновки агрегатов, но и систем самолета.

Существенные изменения в социально-экономической деятельности, информационно-статистическом обеспечении исследований, новые аналитические возможности обработки статистики способствовали необходимости уточнения используемых статистических данных самолетов, необходимых организациям, которые имеют отношение к созданию, развитию и применению авиационных комплексов.

Обобщение изменений параметров и характеристик гражданских легких самолетов начиная с 30-х годов XX века $[2,6,13,12]$ и проведенных исследований современности [3, 9] способствовало определению отличительных и существенных признаков проектирования гражданских легких самолетов.

Исходя из современных требований к авиационной промышленности и к сфрерам ее применения в качестве исследуемого типа летательных аппаратов выбран гражданский легкий самолет с турбовинтовыми двигателями взлетной массой от 2200 до 5700 кг и массой коммерческой нагрузки от 600 до 2000 кг [3, 5].

В связи с созданием новых легких самолетов, их модификаций, изменением данных и усовершенствованием технологий и материалов временным диапазоном данных является период с 1970 до нынешнего времени, что соответствует четвертому этапу развития авиационной техники [13].

Процесс проектирования летательного аппарата состоит из следующих этапов, отражающих сложившуюся технологию его реализации: разработки требований; предварительного проектирования; эскизного проектирования; рабочего проектирования [12, 17].

На этапе разработки требований разрабатывают техническое задание, которое должно удовлетворять заданным перспективным требованиям, соответствующим задачам разных сфер деятельности общества, и обеспечивать высший, чем у прототипов, уровень экономических и эксплуатационных показателей отечественных и зарубежных легких самолетов $[1,5,8,15]$.

В данной работе рассмотрены основные особенности интегрированного проектирования гражданских легких самолетов с турбовинтовыми двигателями на этапе предварительного проектирования.

На этом этапе проведено статистическое исследование параметров и характеристик гражданских легких самолетов и анализ его результатов.

Статистическое исследование выполняли по трем этапам: "Статистическое наблюдение"; "Группировка статистических данных"; "Анализ статистических данных" [3, 4, 10, 11].

К анализу параметров и характеристик гражданских легких самолетов применили методы математической статистики: столбиковые гистограммы, круговые диаграммы и диаграммы рассеивания. 
Аэродинамическую схему самолета характеризует количество и взаимное расположение механизации и стабилизирующих аэродинамических поверхностей, а также органов управления и балансировки.

C учетом развития авиационной науки и техники были разработаны особенности эксплуатируемых аэродинамических схем гражданских легких самолетов и их двигателей с указанием преобладающего процента использования в заданном диапазоне исследования: низкорасположенное крыло - 60 \%; два двигателя с тянущими винтами, горизонтальное оперение, расположенное в хвостовой части фюзеляжа под килем, и убирающееся шасси - $80 \%$; система механизации, состоящая из закрылков и элеронов, - 60 \%; рулевые поверхности с роговой аэродинамической компенсацией - $60 \%$.

Установлены диапазоны изменения удельной нагрузки на крыло $p_{0}$ - от 98,7 до 313,85 даН/м², стартовой энерговооруженности $\mathrm{t}_{0}=0,2585( \pm 0,1055)$, относительной массы коммерческой нагрузки $\bar{m}_{\text {ком }}=0,271( \pm 0,192)$, и относительной массы топлива $\bar{m}_{T}=0,255( \pm 0,171)[3,14]$.

Определены статистические диапазоны геометрических параметров крыла (табл. 1), фрюзеляжа, горизонтального (табл. 2) и вертикального оперения (табл. 3).

Таблица 1

Статистические диапазоны геометрических параметров крыла [3, 15, 14]

\begin{tabular}{|c|c|c|c|c|c|c|c|}
\hline \multirow[b]{2}{*}{$\lambda$} & \multirow[b]{2}{*}{$\eta$} & \multirow[b]{2}{*}{$\begin{array}{l}\chi_{n \kappa}, \\
\text { град }\end{array}$} & \multirow[b]{2}{*}{$\bar{c}$} & \multirow[b]{2}{*}{$S, \mathrm{~m}^{2}$} & \multirow[b]{2}{*}{$\bar{S}_{3}$} & \multicolumn{2}{|c|}{ Угол поперечного $\mathrm{V}_{\text {кр }}$} \\
\hline & & & & & & $\begin{array}{c}\text { для } \\
\text { низкоплана } \\
\mathrm{V}_{\text {кр. н, }}, \text { град } \\
\end{array}$ & $\begin{array}{c}\text { для } \\
\text { высокоплана } \\
\mathrm{V}_{\text {кр. в }}, \text { град } \\
\end{array}$ \\
\hline $7,2 \ldots 12,3$ & $1,0 \ldots 3,24$ & $0 \ldots 5$ & $0,12 \ldots 0,19$ & $16 \ldots 33$ & $0,0177 \ldots 0,362$ & $+4 \ldots+8$ & $-1 \ldots+4$ \\
\hline
\end{tabular}

Статистический интервал высоты фююзеляжа составляет $h=(1,38 \ldots 2,0)$ м, а его ширины $-b=(1,22 \ldots 2,0)$ м.

Таблица 2

Статистические диапазоны относительных геометрических параметров горизонтального оперения [3, 15, 14]

\begin{tabular}{|c|c|c|c|c|c|c|}
\hline$\lambda_{\Gamma О}$ & $\eta_{\Gamma O}$ & $\begin{array}{c}\chi_{\text {пг } Г{ }^{\prime}} \\
\text { град }\end{array}$ & $\bar{c}_{\Gamma O}$ & $\bar{S}_{\Gamma О}$ & $\bar{L}_{\Gamma O}$ & $A_{\Gamma O}$ \\
\hline $3,68 \ldots 6,8$ & $1,0 \ldots 6,88$ & $0 \ldots 42$ & $0,09 \ldots 0,12$ & $0,177 \ldots 0,345$ & $2,816 \ldots 4,719$ & $0,562 \ldots 1,155$ \\
\hline
\end{tabular}

Величина угла поперечного $\mathrm{V}_{\text {го }}$ в зависимости от места его установки принимает различные значения: для ЛА с ГО, расположенным на фююзеляже (палубное ГО), $-0 \ldots+11^{\circ}$; для ЛА с ГО, расположенным на киле (при разной величине удаления от оси фрюзеляжа), $-0,+13^{\circ}$; для ЛА с Т-образным ГО $-0,-5^{\circ}$.

Таблица 3

Статистические диапазоны относительных геометрических параметров вертикального оперения [3, 15, 14]

\begin{tabular}{|c|c|c|c|c|c|}
\hline$\lambda_{\text {BO }}$ & $\eta_{\text {BO }}$ & $\begin{array}{c}\chi_{n \kappa \text { вO }} \\
\text { град }\end{array}$ & $\bar{S}_{B O}$ & $\bar{L}_{B O}$ & $A_{B O}$ \\
\hline $0,765 \ldots 1,78$ & $1,34 \ldots 3,68$ & $0 \ldots 49$ & $0,09 \ldots 0,319$ & $0,241 \ldots 0,548$ & $0,0268 \ldots 0,116$ \\
\hline
\end{tabular}


Статистические диапазоны относительной площади рулевых поверхностей находятся в пределах: для руля высоты $-\bar{S}_{p .8}=0,34 \ldots 0,472 ;$ для руля направления $-\bar{S}_{p . н}=0,211 \ldots 0,491[3,15,14]$.

В случае сравнения самолетов при постоянных значениях дальности, крейсерской скорости, полезной нагрузки и т.д. экономические критерии трансформируются в общепринятый и наиболее доступный критерий - взлетную массу самолета [13].

Определение критериев, позволяющих на каждом иерархическом уровне объективно оценивать результаты проектирования, находить для каждого агрегата и систем легкого самолета такие параметры, которые обеспечивают высокую эффеектиность ЛА в целом, - важный этап формализации проектной задачи.

На этапе предварительного проектирования (в нулевом, первом, втором и третьем приближениях) предложен метод определения взлетной массы гражданских легких самолетов с турбовинтовыми двигателями взлетной массой от 2200 до 5700 кг с массой коммерческой нагрузки от 600 до 2000 кг [15].

В качестве критерия оптимальности принята минимальная взлетная масса $m_{0} \rightarrow \min$ при обеспечении основных тактико-технических требований.

Современный этап развития легкой авиации характеризуется ее усложнением и соответственно относительно высокими затратами фринансовых и временных ресурсов, что существенно ограничивает производственные возможности.

Исходя из этого результатом нулевого приближения рекомендовано считать разработку чертежа общего вида проектируемого самолета и расчет его аэродинамических характеристик, что позволит принять наиболее важное решение о продолжении работы над проектом в случае удовлетворения техническому заданию и изменении основных относительных геометрических параметров - при его неудовлетворении и повторном выполнении этапов нулевого приближения.

Достижение критерия минимума массы возможно благодаря применению разработанного метода расчета взлетной массы в первом приближении, основой которого стало введение полученных поправочных статистических коэффициентов, позволяющих получить близкие к действительным величины параметров нового гражданского легкого самолета, в существующий метод расчета взлетной массы самолетов [5].

Исследование влияния геометрических параметров на аэродинамические, энергетические и массовые характеристики и параметры осуществлено в целях определения минимальной взлетной массы самолета и оптимальных параметров (удельной нагрузки на крыло; удлинения, сужения, стреловидности, относительной толщины профиля; энерговооруженности и т.д.).

Для реализации алгоритма совершенствования расчета взлетной массы разработан программный комплекс циклического характера $[5,15]$. Он позволяет задавать исходные данные, редактировать их в процессе работы, выполнять расчеты, выводить результаты в формате $x \mathrm{ml}$ и перемещать их в табличные процессоры, строить графические зависимости для непосредственной оценки исходных данных в процессе расчета.

Программный комплекс апробирован авторами при расчете современных легких самолетов, а именно: A-Viator, Рысачок, King Air C90 GTx, Cessna 441, a 
также Ан-14 и при выполнении дипломных проектов студентами первого и второго курсов магистратуры.

Метод определения взлетной массы гражданских легких самолетов с турбовинтовыми двигателями, учитывающий наиболее важные особенности интегрированного проектирования, апробирован при разработке аванпроекта нового гражданского легкого самолета с турбовинтовыми двигателями ХАИ-90.

Гражданский легкий самолет ХАИ-90 представляет собой свободнонесущий моноплан с высокорасположенным крылом, однокилевым вертикальным оперением, горизонтальным оперением, расположенным в хвостовой части фюзеляжа, и убирающимся трехопорным шасси с носовой стойкой.

Силовая установка проектируемого самолета состоит из двух турбовинтовых двигателей с тянущими винтами, установленных под крылом, их агрегатов и систем, воздухозаборников.

Применение классической схемы самолета ХАИ-90, наличие механизации (элеронов, закрылков, предкрылков) и органов управления (рулей высоты и направления) обеспечивает высокую устойчивость и управляемость на всех режимах полета.

Выполнение самолета по схеме высокоплан с двигателями, расположенными в крыле, позволяет эксплуатировать, как с бетонных, так и с грунтовых и травяных покрытий. При этом элементы силовой установки защищены от попадания загрязнений и мелких частиц с поверхности земли, что повышает ресурс и надежность их работы. Применение современных специальных двигателей, предназначенных для легких самолетов, обеспечивает снижение удельного расхода топлива и уровня шума на местности.

Высота самолета и высота расположения двигателей по вертикали от земли позволяют выполнять работы по осмотру и обслуживанию с помощью небольшой стремянки $(h=1 \mathrm{~m})$.

По решению Заказчика может быть установлен один из рассмотренных двух типов силовых установок с современными двигателями: газотурбинным двигателем АИ-450С украинского производства предприятия "Мотор Січ" взлетной мощностью $N_{0}=450$ л.с. каждый и турбовинтовым двигателем Rolls-Royce 250-B17F британской компании Rolls-Royce взлетной мощностью $N_{0}=420$ л.с. каждый.

Основные тактико-технические требования (ТTТ), которые в наибольшей степени соответствуют Нормам летной годности гражданских легких самолетов АП-23 (CS-23, JAR-23) [7], приведены в табл. 4.

Основные тактико-технические требования

Таблица 4 гражданского легкого самолета ХАИ-90

\begin{tabular}{|c|c|c|c|c|c|c|c|c|c|c|}
\hline$M_{\text {max }}$ & $\begin{array}{c}L_{\text {max }}, \\
\text { км }\end{array}$ & $\begin{array}{c}n_{n a c}, \\
\text { чел. }\end{array}$ & $\begin{array}{c}L_{p}, \\
\mathrm{M}\end{array}$ & $\begin{array}{c}H_{n o m}, \\
\mathbf{M}\end{array}$ & $\begin{array}{c}V_{\kappa p}, \\
\text { км/ч }\end{array}$ & $\begin{array}{c}t_{\text {наб }}, \\
\text { мин }\end{array}$ & $\begin{array}{c}n_{э к}, \\
\text { чел. }\end{array}$ & $\begin{array}{c}H_{\kappa p}, \\
\mathbf{M}\end{array}$ & $K_{\kappa p}$ & $\begin{array}{c}T, \\
\mathbf{4}\end{array}$ \\
\hline 0,35 & 1500 & 6 & 300 & 7000 & 350 & 5 & 1 & 3500 & $14 \ldots 15$ & 20000 \\
\hline
\end{tabular}

Выполнено сравнение минимальной взлетной массы ХАИ-90 по разработанному методу с массами самолетов-прототипов (табл. 5). 
Таблица 5

Величины взлетных масс ХАИ-90 и самолетов-прототипов

\begin{tabular}{|l|c|c|c|c|c|c|}
\hline $\begin{array}{l}\text { Название } \\
\text { самолета }\end{array}$ & A-Viator & Рысачок & $\begin{array}{c}\text { King Air } \\
\text { C90 GTx }\end{array}$ & Cessna 441 & Ан-14 & ХАИ-90 \\
\hline $\begin{array}{l}\text { Минимальная } \\
\begin{array}{l}\text { взлетная масса } \\
m_{0 \text { min }}, \text { кг }\end{array}\end{array}$ & 3000 & 6820 & 4756 & 4468 & 3500 & 3430 \\
\hline
\end{tabular}

По результатам метода определения взлетной массы гражданских легких самолетов с турбовинтовыми двигателями ХАИ-90 разработан чертеж общего вида (рис. 1).
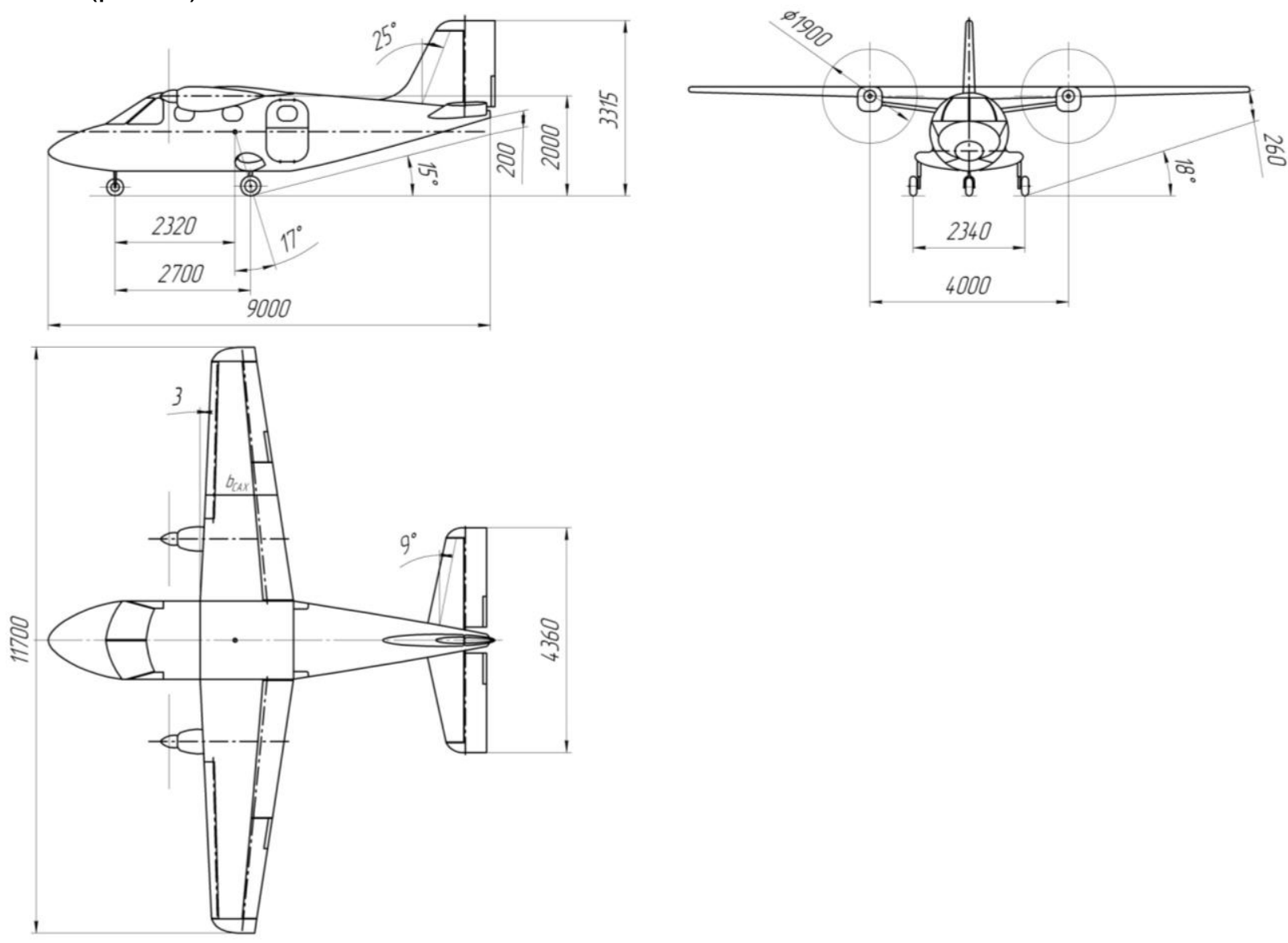

Рис. 1. Фрагмент чертежа общего вида самолета ХАИ-90 [1, 8]

Далее следует приступить к созданию трехмерной компьютерной модели самолета. Авторами рекомендовано применить метод трехмерного параметрического моделирования, который позволит выполнять преобразование модели самолета, воспроизводя тем самым ее собственный способ создания, изменять построенные на ранних этапах элементы и автоматически перестраивать всю геометрию созданную позже.

Компьютерный проект самолета разрабатываем с помощью системы Siemens NX. Он включает в себя следующие модели [16]:

- модель № 1. Мастер-геометрия самолета.

Создание модели гражданского легкого самолета проводят путем ее разделения на отдельные агрегаты (крыло, фрюзеляж, горизонтальное, 
вертикальное оперение, мотогондолы и пилоны, шасси), каждый из которых должен состоять из набора сегментов.

Для каждого сегмента (или агрегата) выполняют построение поверхности теоретического контура (ТК) по набору кривых, описывающих его ТК.

Фрагмент мастер-геометрии гражданского легкого самолета ХАИ-90 показан на рис. 2;

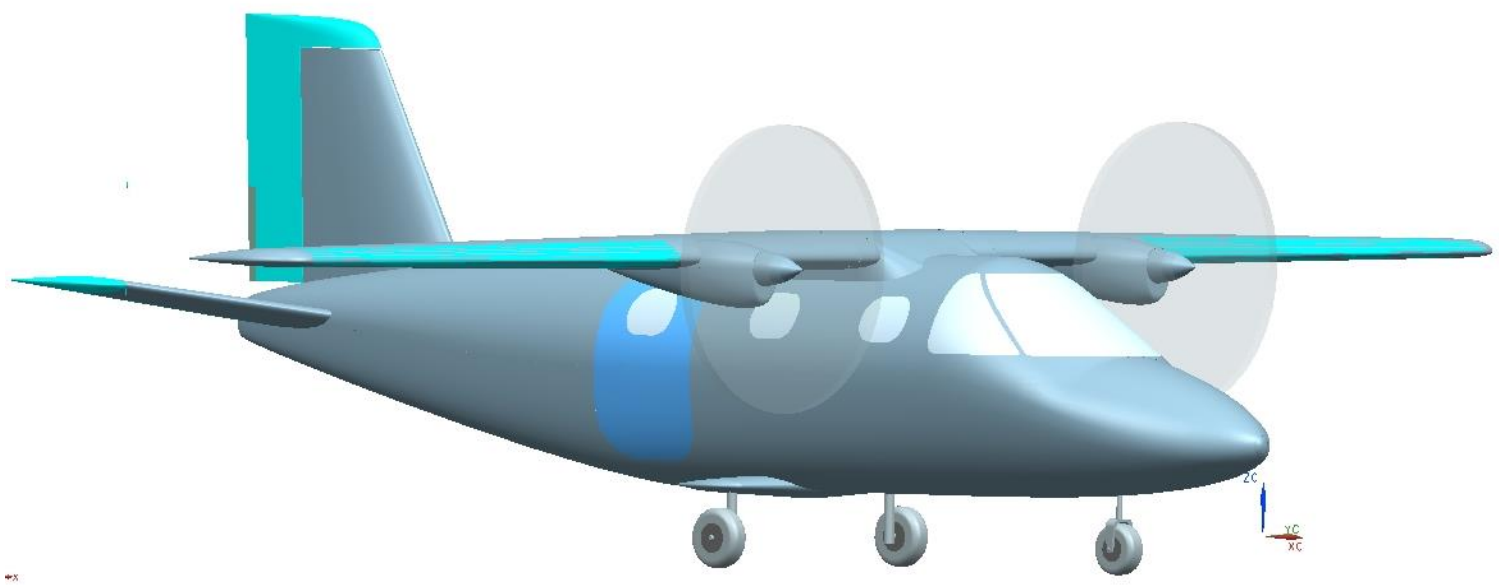

Рис. 2. Фрагмент мастер-геометрии самолета ХАИ-90 [1, 8]: вид с левого борта фюзеляжа

- модель № 2. Модель распределения пространства.

Предложено создавать набор кривых, определяющих положение элементов конструктивно-силовой схемы каждого сегмента (или агрегата) и построить серединные плоскости элементов.

Фрагмент модели распределения пространства гражданского легкого самолета ХАИ-90 показан на рис. 3;

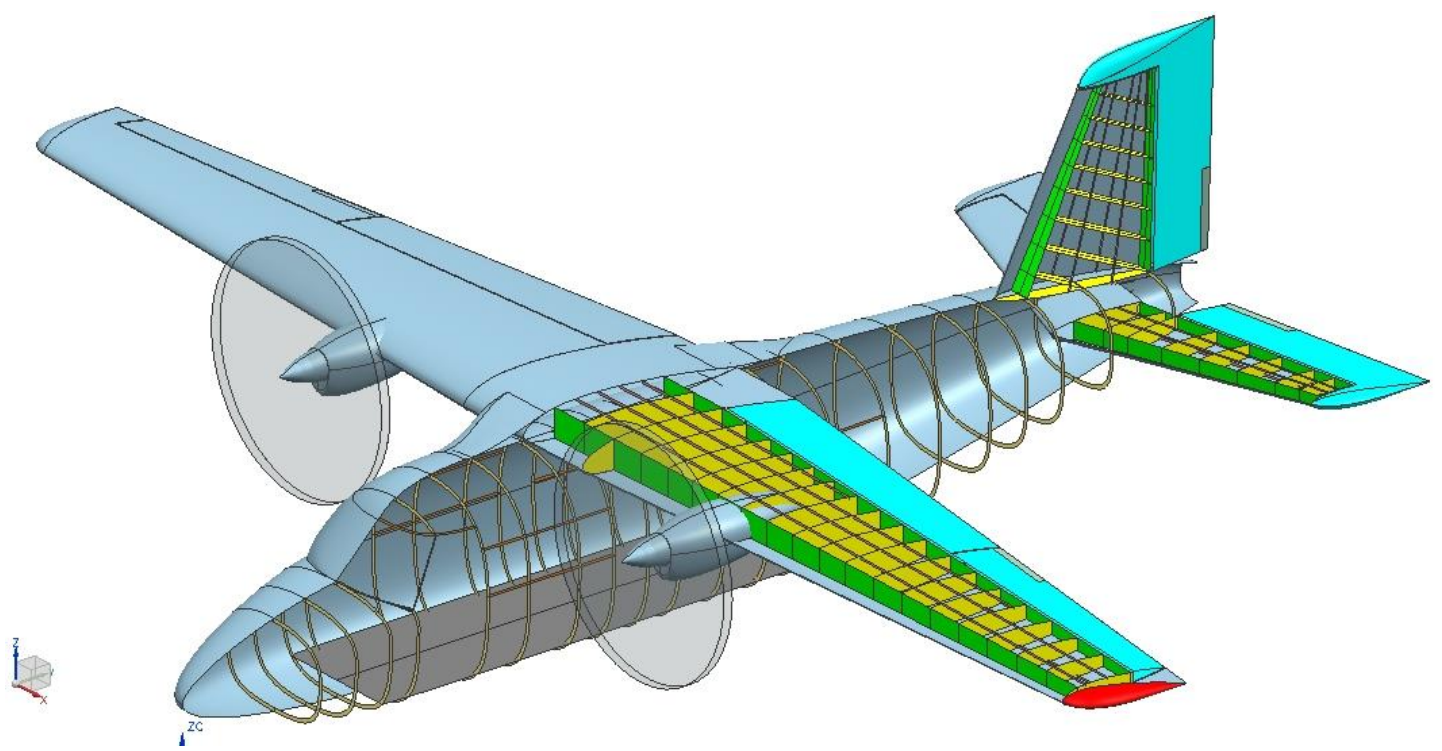

Рис. 3. Фрагмент модели распределения пространства самолета ХАИ-90 [1]

- модель № 3. Модель стыков и соединений по конструктивнотехнологическим разъемам.

Разработка модели № 3 предполагает создание трехмерных моделей 
деталей силового набора, обшивок и узлов навески, конструкции соединений и стыков с учетом их взаимной увязки.

Пример аналитических эталонов элементов конструкции стабилизатора гражданского легкого самолета ХАИ-90 показан на рис. 4;

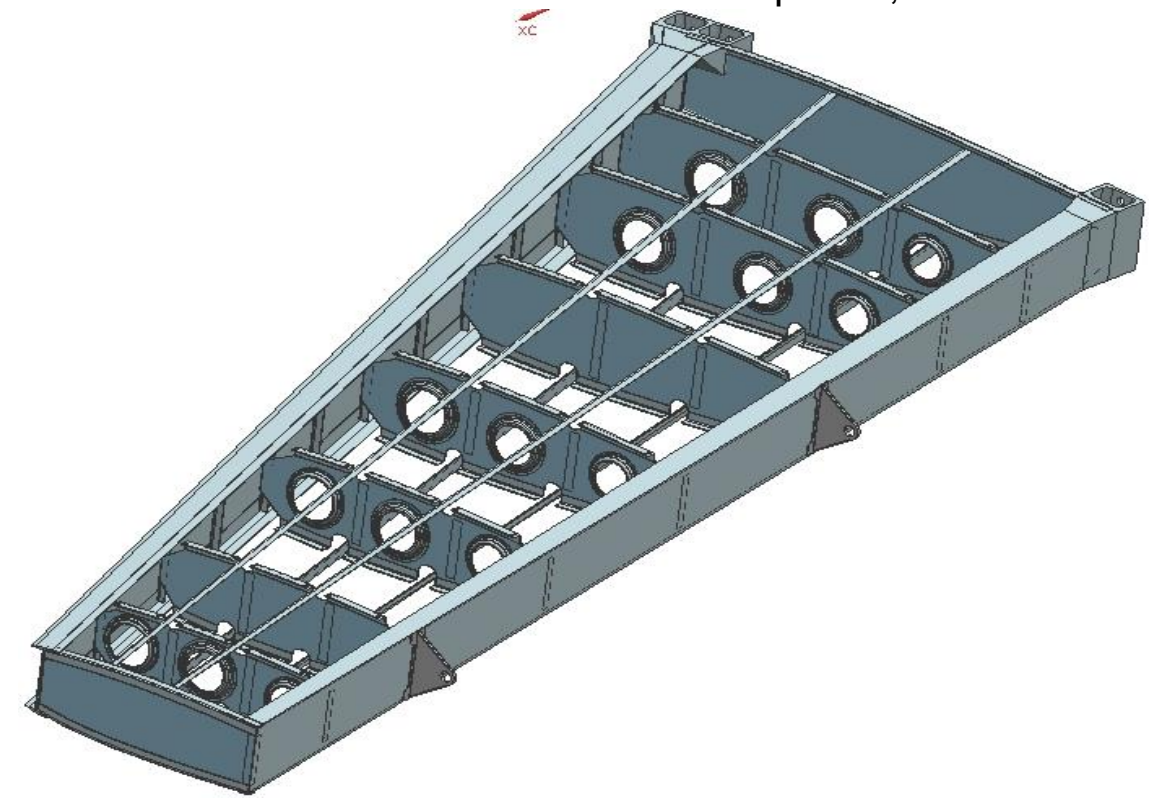

Рис. 4. Аналитические эталоны элементов конструкции стабилизатора

- модель № 4. Модель геометрии всего изделия.

Модель полного компьютерного определения самолета основана на моделях № 1, 2 и 3, а также на моделировании элементов всех систем, расположенных на самолете.

\section{Выводы}

Определены основные особенности интегрированного проектирования гражданских легких самолетов с турбовинтовыми двигателями на этапе предварительного проектирования:

- в качестве исследуемого типа летательных аппаратов выбран гражданский легкий самолет с турбовинтовыми двигателями взлетной массой от 2200 до 5700 кг с массой коммерческой нагрузки от 600 до 2000 кг, что необходимо для удовлетворения современных требований сфер деятельности человека;

- анализ исторических изменений параметров и характеристик гражданских легких самолетов позволил установить и уточнить их пределы изменения и статистические диапазоны;

- принятие наиболее важного решения при проектировании легкого самолета о продолжении работы над проектом дает возможность получить результаты этапа предварительного приближения разработанного метода определения взлетной массы самолета;

- в качестве критерия оптимальности принята минимальная взлетная масса самолета $m_{0} \rightarrow \min$. Ее величина достигается путем исследования влияния его геометрических параметров на аэродинамические, энергетические и массовые характеристики и параметры;

- введение поправочных статистических коэффрициентов в исследование 
методом последовательных приближений, выраженных уравнениями регрессии, позволяет получить величины параметров нового гражданского легкого самолета, удовлетворяющие техническое задание;

- определение геометрических, аэродинамических, энергетических и массовых характеристик и параметров гражданского легкого самолета в нулевом, первом, втором и третьем приближениях проводят по разработанному программному комплексу циклического характера;

- апробация метода определения взлетной массы выполнена при проектировании нового гражданского легкого самолета ХАИ-90 и разработке его аванпроекта. Величина его минимальной взлетной массы меньше, чем у прототипов, в 1,3 раза, что соответствует $4 \%$;

- моделирование гражданских легких самолетов основано на иерархическом проектировании, при котором определяющее значение имеет порядок создания элементов, который отражается в дереве построения модели. Поскольку проектируемый тип самолетов имеет уровень сложности конструкции и ее конструктивных элементов ниже, чем у средних и тяжелых самолетов, а затраты на процесс создания проекта выше (в том числе вследствие поштучного или мелкосерийного производства), то особое место занимает правильно созданный алгоритм построения модели, позволяющий сократить временные и ресурсные затраты.

\section{Список литературы}

1. Буйвал, Л. Ю. Метод определения взлетной массы многоцелевого гражданского легкого самолета укороченного взлета и посадки на этапе предварительного проектирования [Текст] / А. М. Гуменный, Л. Ю. Буйвал // Открытые информационные и компьютерные интегрированные технологии: сб. науч. тр. Нац. аэрокосм. ун-та им. Н.Е. Жуковского «ХАИ». - Вып. 65. - Х., 2014. - С. 23 41.

2. Шейнин, В.М. Весовое проектирование и эфффективность пассажирских самолетов [Текст]: учеб. пособие. - Т. 1 / В. М. Шейнин, В. И. Козловский. М.: Машиностроение, 1977. - 344 с.

3. Буйвал, Л.Ю. Статистическое исследование параметров и характеристик гражданских легких самолетов с турбовинтовыми двигателями [Текст] / А.М. Гуменный, Л.Ю. Буйвал // Открытые информационные и компьютерные интегрированные технологии: сб. науч. тр. Нац. аэрокосм. ун-та им. Н.Е. Жуковского «ХАИ». - Вып. 71. - Х., 2016. - С. $30-45$.

4. Борздова, Т. В. Основы статистического анализа и обработка данных с применением Microsoft Exel [Текст]: учеб. пособие / Т. В. Борздова. - Минск: ГИУСТ БГУ, 2011. - 75 c.

5. Буйвал, Л.Ю. Алгоритм и программа совершенствования расчета взлетной массы в первом приближении гражданского легкого самолета с турбовинтовыми двигателями [Текст] / А. Г. Гребеников, А. М. Гуменный, Л. Ю. Буйвал // Открытые информационные и компьютерные интегрированные технологии: сб. науч. тр. Нац. аэрокосм. ун-та им. Н. Е. Жуковского «ХАИ». Вып. 73. - Х., 2016. - С. 166 - 179.

6.Бадягин, А.А. Проектирование легких самолетов [Текст] / А.А. Бадягин, Ф.А. Мухаммедов. - М.: Машиностроение, 1978. - 208 с. 
7. Авиационные правила. Ч. 23. Нормы летной годности гражданских легких самолетов. - МАК, 1993.

8. Буйвал, Л.Ю. Аванпроект гражданского легкого многоцелевого самолета [Текст] / Л.Ю. Буйвал, А.М. Гуменный // Открытые информационные и компьютерные интегрированные технологии: сб. науч. тр. Нац. аэрокосм. ун-та им. Н.Е. Жуковского «ХАИ». - Вып. 63. - Х., 2014. - С. $197-211$.

9. Арепьев, А.И. Вопросы проектирования легких самолетов. Выбор схемы и основных параметров [Текст] / А.И. Арепьев. - М.: МАИ, 2001. - 134 с.

10. Боровиков, В. STATISTICA. Искусство анализа данных на компьютере: Для профрессионалов [Текст]: 2-е изд. / В. Боровиков. - СПб.: Питер, 2003. - 688 с.

11. Степанова, Н. И. Статистика. Ч.ІІ (статистика гражданской авиации) [Текст]: учеб. пособие / Н. И. Степанова. - М.: МГТУ ГА, 2002. - 83 с.

12. Торенбик, Э. Проектирование дозвуковых самолетов [Текст] / Э. Торенбик; пер. с англ. / Е. П. Голубкова. - М.: Машиностроение, 1983. - 648 с.

13. Машиностроение. Энциклопедия / ред. совет: К.В. Фролов (пред.) и др. М.:Машиностроение. Самолеты и вертолеты. T. IV-21. Проектирование, конструкции системы самолетов и вертолетов. Кн. 2 / А.М. Матвеенко, А.И. Акимов, М.Г. Акопов и др.; под. общ. ред. А.М. Матвиенко. - 752 с.

14. Буйвал, Л.Ю. Анализ параметров и характеристик гражданских легких самолетов с турбовинтовыми двигателями [Текст] / А.М.Гуменный, Л.Ю. Буйвал // Проблеми створення та забезпечення життєвого циклу авіаційної техніки: міжнар. наук.-техн. конф.: тези доп., 20-21 квіт. 2016 р. / М-во освіти і науки України, Нац. аерокосм. ун-т ім. М. Є. Жуковського «XАl». - Х., 2016. - С. 27.

15. Буйвал, Л.Ю. Метод определения взлетной массы гражданских легких самолетов с турбовинтовыми двигателями [Текст] / А.Г.Гребеников, А. М. Гуменный, Л. Ю. Буйвал // Открытые информационные и компьютерные интегрированные технологии: сб. науч. тр. Нац. аэрокосм. ун-та им. Н.Е. Жуковского «ХАИ». - Вып. 78. - Х., 2018. - С. 18 - 35.

16. Гребеников, А.Г. Методология интегрированного проектирования и моделирования сборных самолетных конструкций / А.Г. Гребеников. - X: Нац. аэрокосм. ун-т им. Н.Е. Жуковского «ХАИ», 2006. - 532 с.

17. Проектирование самолетов [Текст]: учебник для вузов. - 3-е изд., перераб. и доп. / С. М. Егер, В. Ф. Мишин, Н. К. Лисейцев и др. - М.: Машиностроение, 1983. $-616 \mathrm{c}$. 


\section{Особливості інтегрованого проектування цивільних легких літаків 3 турбогвинтовими двигунами на етапі попереднього проектування}

Проведено аналіз змін параметрів і характеристик цивільних легких літаків. Запропоновано нові шляхи підвищення їх якості, поліпшення тактико-технічних і льотних характеристик для задоволення широкого спектра сфрер їх застосування. Установлено межі змін й уточнено статистичні діапазони параметрів і характеристик цивільних легких літаків. Наведено рекомендації щодо методу визначення злітної маси цивільного легкого літака з турбогвинтовими двигунами на етапі попереднього проектування відповідно до критерію оптимальності мінімальної злітної маси. Описано особливості програмного комплексу та його апробацію при розробленні аванпроекту цивільного легкого літака XAI-90.

Ключові слова: цивільний легкий літак, злітна маса, етап попереднього проектування, критерій мінімуму маси, майстер-геометрія, модель розподілу простору, аналітичний еталон, статистичне дослідження.

\section{Features of the Integrated Design of Turboprop Civil Light Aircraft at the Preliminary Design Stage}

The analysis of changes in the parameters and characteristics of civilian light aircraft. New ways of improving its quality, improving tactical, technical and flight characteristics to meet a wide range of areas of its using have been proposed. The limits of change are established and the statistical ranges of parameters and characteristics of civilian light aircraft are refined. Recommendations are given on the method for determining the take-off mass of a civilian light aircraft with turboprop engines at the preliminary design stage in accordance with the optimality criterion - the minimum take-off mass. The features of the software package and its approbation during the development of KhAl-90 civil light aircraft preliminary project are described.

Key words: civil light aircraft, take-off weight, approximation, preliminary design stage, mass minimum criterion, master geometry, space distribution model, analytical standard, statistical study.

\section{Сведения об авторах:}

Александр Григорьевич Гребеников - д-р техн. наук, профресcop, заведующий кафедрой 103 «Проектирование самолетов и вертолетов», Национальный аэрокосмический университет им. Н. Е. Жуковского «Харьковский авиационный институт», Украина.

Андрей Михайлович Гуменный - канд. техн. наук, доцент кафедры 103 «Проектирование самолетов и вертолетов», Национальный аэрокосмический университет им. Н. Е. Жуковского «Харьковский авиационный институт», Украина.

Лилия Юрьевна Буйвал - ассистент кафедры 103 «Проектирование самолетов и вертолетов», Национальный аэрокосмический университет им. Н. Е. Жуковского «Харьковский авиационный институт», Украина. 